\title{
Microstructural Characterization and Thermal Properties of Aluminium Titanate/YSZ Ceramics
}

\author{
E. CITAK $^{a, b}$ AND T. BOYRAZ ${ }^{a, *}$ \\ ${ }^{a}$ Cumhuriyet University, Metallurgical and Materials Engineering, Sivas, Turkey \\ ${ }^{b}$ Erciyes University, Fine Arts, Kayseri, Turkey
}

\begin{abstract}
Yttria stabilized zirconia (YSZ, with 3 mol.\% $\mathrm{Y}_{2} \mathrm{O}_{3}$ ) has superior high temperature properties such as high tolerance for thermal shock, low thermal conductivity, mechanical properties, elevated melting point, good phase stability, and excellent oxidation resistance. Aluminium titanate $\left(\mathrm{Al}_{2} \mathrm{TiO}_{5}\right)$ exhibits extremely good thermal shock resistance and low thermal conductivity coupled with good chemical resistance in molten metals. In the present work, aluminium titanate/YSZ ceramics with different percentages of $\mathrm{Al}_{2} \mathrm{TiO}_{5}$ was prepared using powder metallurgy techniques. The microstructural, mechanical and thermal properties were characterized using X-ray diffraction, scanning electron microscopy, differential scanning calorimetry, dilatometer and hardness. Thermal shock resistance behaviour under water quenching of the as-prepared ceramics was also evaluated. The results revealed that the addition of aluminium titanate to YSZ matrix improves the properties of the aluminium titanate/ YSZ ceramics.
\end{abstract}

DOI: $10.12693 /$ APhysPolA.125.465

PACS: 81.05.Mh

\section{Introduction}

Pure zirconia in equilibrium state exists in three polymorphic forms: the monoclinic phase is stable up to $1170^{\circ} \mathrm{C}$ where it transforms into the tetragonal phase, which is stable up to $2370^{\circ} \mathrm{C}$, and the cubic phase exists up to the melting point at $2680^{\circ} \mathrm{C}[1,2]$. Obtaining of stable sintered zirconia ceramic products is difficult because of the large volume change accompanying the transition from tetragonal to monoclinic (about 9\%). Stabilization of the tetragonal polymorph of zirconia over wider range of temperatures is accomplished by substitution of some of the $\mathrm{Zr}^{4+}$ ions in the crystal lattice with slightly larger ions, e.g., those of $\mathrm{Y}^{3+}$ (ionic radius of $0.96 \AA$ ). The resulting doped zirconia materials are termed stabilized zirconia [3]. The superior mechanical such as hardness, strength and fracture toughness, thermal such as high tolerance for thermal shock, low thermal conductivity, electrical and chemical properties of yttria stabilized zirconia have recently become the focus of growing scientific and technological interest $[4,5]$.

The aluminium titanate is a one mole alumina $\left(\mathrm{Al}_{2} \mathrm{O}_{3}\right)$ and one mole titania $\left(\mathrm{TiO}_{2}\right)$ compound. This material is conventionally prepared by reactive sintering of $\mathrm{Al}_{2} \mathrm{O}_{3}$ and $\mathrm{TiO}_{2}$ powders [6]. Aluminium titanate $\left(\mathrm{Al}_{2} \mathrm{TiO}_{5}\right)$ ceramics are excellent thermal shock resistant materials on account of their unique combination of low thermal expansion, low Young modulus, low thermal conductivity, and high melting point [7-10]. It is these properties that make $\mathrm{Al}_{2} \mathrm{TiO}_{5}$ suitable for high-temperature

*corresponding author; e-mail: tahs inboyraz@cumhuriyet.edu.tr applications where thermal shock resistance and thermal insulation is required, such as components of internal combustion engines, exhaust port liners, swirl chambers, valves, piston buttons, turbochargers, and manifold insulations. Other important applications include thermocouple sleeves, burner nozzles and it is widely used as refractory crucibles for metal casting and flow regulation $[9,11]$.

In the literature, Wei et al. prepared $\mathrm{ZrO}_{2}-\mathrm{Al}_{2} \mathrm{TiO}_{5}$ composite materials with high bending strength and good thermal shock resistance expansion using partially stabilized zirconia (Y-PSZ) powders coated with $\mathrm{Al}_{2} \mathrm{TiO}_{5}$ by co-precipitation method [12]. Shimada et al. found that aluminium titanate was strengthened by alloying with 3 mol.\% yttria stabilized zirconia to attain a small expansion coefficient of $2 \times 10^{-6}$ and a high strength of $100 \mathrm{MPa}$ [13].

In this study aluminium titanate/YSZ ceramics with different percentages of $\mathrm{Al}_{2} \mathrm{TiO}_{5}$ was prepared, microstructural physical, mechanical and thermal properties were characterized.

\section{Experimental}

In this study, zirconia (Serp, France), 3 mol.\% yttria $\left(\mathrm{Y}_{2} \mathrm{O}_{3}\right.$, Merck, Germany) was used for obtaining yttria stabilized zirconia stoichiometric composition (YSZ, with $\left.3 \mathrm{~mol} . \% \mathrm{Y}_{2} \mathrm{O}_{3}\right)$ and aluminum titanate $\left(\mathrm{Al}_{2} \mathrm{TiO}_{5}\right)$ was produced by using alumina $\left(\mathrm{Al}_{2} \mathrm{O}_{3}\right.$, Merck, Germany) and titania $\left(\mathrm{TiO}_{2}\right.$, Merck, Germany) powders. Starting materials that we use are regarded as $99.9 \%$ percent pure. After the zirconia and yttria were weighed in terms of mole ratio of YSZ, with $3 \mathrm{~mol} . \% \mathrm{Y}_{2} \mathrm{O}_{3}$ mixtures were dispersed in acetone and milled as wet with zirconia balls of $\varnothing 10 \mathrm{~mm}$ for $3 \mathrm{~h}$. The materials containing $\mathrm{Al}_{2} \mathrm{O}_{3}$ and $\mathrm{TiO}_{2}$ were prepared in the same way 
by wet ball milling. $\mathrm{Al}_{2} \mathrm{TiO}_{5}$ ceramics were synthesized by reaction sintering of an equimolar mixture of $\mathrm{Al}_{2} \mathrm{O}_{3}$ and $\mathrm{TiO}_{2}$ powders. The powders were first homogenized by wet ball milling. The resulting mixtures were then sintered at $1550{ }^{\circ} \mathrm{C}$ for $\mathrm{YSZ}$ and $1600{ }^{\circ} \mathrm{C}$ for aluminium titanate (AT) in air for $2 \mathrm{~h}$. Then, additions of AT in weight proportions of $0,5,10 \mathrm{wt} \%$ were made to the ZAT (YSZ+AT) mixture (hereafter these mixtures are denoted ZAT0, ZAT5, and ZAT10, respectively). Each lot was again wet mixed according to the procedure described above. Then, we pressed mixtures at $200 \mathrm{MPa}$ into $30 \times 30 \times 5 \mathrm{~mm}^{3}$ specimens. The compacts were sintered in air using a heating rate of $5^{\circ} \mathrm{C} \mathrm{min}^{-1}$, soaked at $1700^{\circ} \mathrm{C}$.

Bulk density, porosity and water absorption of the sintered samples were measured. Micro hardness (Shimadzu, HMV) was measured on the polished surface of the samples at room temperature. At least six individual tests with a peak load of $2000 \mathrm{~g}$ and a loading time of $20 \mathrm{~s}$ were performed for each set of composites. After sample sections were mechanically polished and then thermally etched at $1500^{\circ} \mathrm{C}$ for $4 \mathrm{~h}$ in air, the microstructural characterization of the sintered samples was carried out using scanning electron microscopy (SEM) (Leo 440). The morphological parameters of the various phases were characterized by using a semiautomatic image analyzer, energy dispersive X-ray spectroscopy (EDX) and the formed phases were analyzed by $\mathrm{X}$-ray powder diffractometer (Rigaku, Dmax, IIIC) using $\mathrm{Cu} K_{\alpha}$ radiation. The thermal behavior of the ZAT composition was characterized by differential scanning calorimetry (DSC) (Shimadzu, DSC-60). Thermal expansion coefficients were measured by using dilatometer (Anter, USA).

\section{Result and discussion}

Table shows physical properties of the sintered ZAT ceramics obtained for the different mixtures prepared. Both the bulk and true densities of the composites decreased with increasing aluminium titanate content. (Note that the theoretical density of ZAT0 is $6.05 \mathrm{~g} \mathrm{~cm}^{-3}$ whereas the density of $\mathrm{Al}_{2} \mathrm{TiO}_{5}$ is $3.20 \mathrm{~g} \mathrm{~cm}^{-3}$ [14].) Also evident in Table is that the porosity and water absorption decreased from 0 to $10 \mathrm{wt} \% \mathrm{Al}_{2} \mathrm{TiO}_{5}$ content.

Physical properties of sintered samples.

TABLE

\begin{tabular}{c|c|c|c|c|c}
\hline \hline & $\begin{array}{c}\rho_{\text {bulk }} \\
{\left[\mathrm{g} / \mathrm{cm}^{3}\right]}\end{array}$ & $\begin{array}{c}\rho_{\text {true }} \\
{\left[\mathrm{g} / \mathrm{cm}^{3}\right]}\end{array}$ & $\begin{array}{c}\rho_{\text {relative }} \\
{[\%]}\end{array}$ & $\begin{array}{c}\text { Porosity } \\
{[\%]}\end{array}$ & $\begin{array}{c}\text { Water } \\
\text { absorption } \\
{[\%]}\end{array}$ \\
\hline \multicolumn{5}{c}{ Sintered at $1700{ }^{\circ} \mathrm{C}$} \\
ZAT0 & 5.89 & 6.05 & 97.38 & 2.625 & 1.750 \\
ZAT5 & 5.88 & 5.91 & 99.59 & 0.405 & 0.264 \\
ZAT10 & 5.75 & 5.77 & 99.82 & 0.181 & 0.114
\end{tabular}

Figure 1 is representative SEM micrographs taken from the surface of the sintered ZAT0, ZAT5, and ZAT10 samples. It can be seen that ZAT10 appears to be denser and fewer pores than the sample ZAT5 and ZAT5 appears to be denser and fewer pores than the sample ZAT0. As received, denser structure was observed with increasing aluminium titanate content. The addition of aluminum titanate also influences the grain morphology as is observed in the microstructures of the composites. The grain size is growing as the amount of aluminum titanate increases. EDX shows that microstructure of ZAT10 sample was used for phase analysis. Region A consists of two main phases ( $\mathrm{YSZ}$ and $\mathrm{Al}_{2} \mathrm{TiO}_{5}$ ) because it contained $\mathrm{Zr}, \mathrm{O}$, $\mathrm{Y}, \mathrm{Al}$, and Ti. Region $\mathrm{B}$ is consisting of $\mathrm{Zr}, \mathrm{O}, \mathrm{Y}$, and Ti. Region $\mathrm{C}$ is consisting of $\mathrm{Zr}, \mathrm{O}, \mathrm{Ti}$, and $\mathrm{Y}$. Titanium content was found as $2.76 \%$ in the general EDX analysis (A), $2.38 \%$ within the grain structure $(\mathrm{B})$ and $3.43 \%$ at the grain border (C). Hence, $\mathrm{TiO}_{2}$ is more intense at grain borders. The average grain size determined $2.1 \mu \mathrm{m}$ for ZAT0, $5.4 \mu \mathrm{m}$ for ZAT5, and $7.8 \mu \mathrm{m}$ for ZAT10.
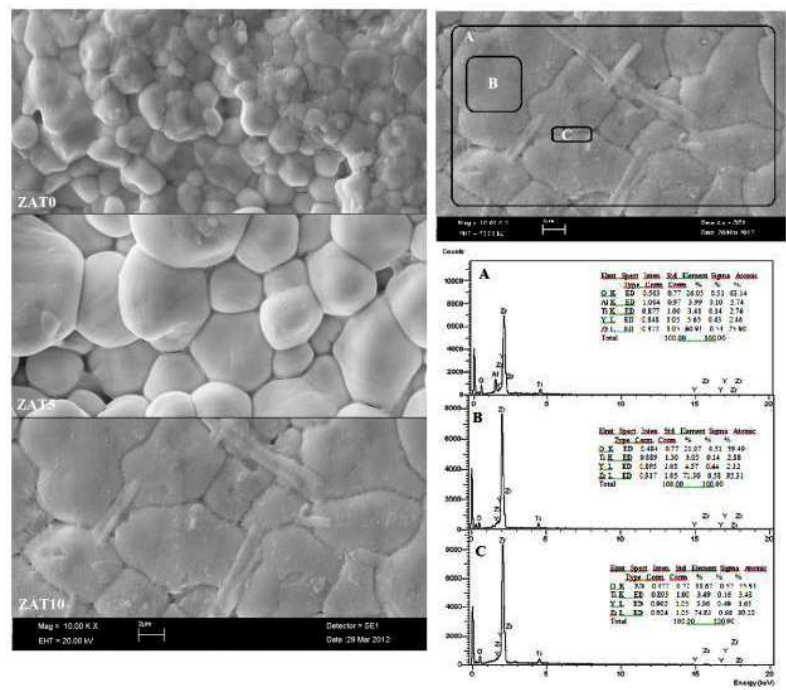

Fig. 1. SEM and EDX images analyses of ZAT0, ZAT5, and ZAT10.

The X-ray diffraction patterns of the aluminium titanate and ZAT10 are shown in Fig. 2. XRD analysis of the as-sintered samples revealed that main phases are YSZ and aluminum titanate. Results showed that monoclinic and tetragonal phases appeared in the samples.

The thermal behavior of the YSZ, AT, and ZAT10 ceramics were characterized by differential scanning calorimetry (DSC) in Fig. 3. The first exothermic peak for YSZ at 300 and $350^{\circ} \mathrm{C}$ are observed in the DSC plot. As indicated above, this fact suggests the loss of lattice water and organic functional groups. Another exothermal peak is also observed around $480^{\circ} \mathrm{C}$, which could be due to the crystallization of the cubic (c) and tetragonal (t) phases [15].

The thermal expansion behavior of ZAT0 and ZAT10 ceramics are shown in Fig. 4. ZAT0 has a coefficient of thermal expansion (CTE) of $10.8 \times 10^{-6} \mathrm{~K}^{-1}$ for $3 \mathrm{~mol} . \%$ YSZ in the range 298 and $1273 \mathrm{~K} \mathrm{[16].}$ $\mathrm{Al}_{2} \mathrm{TiO}_{5}$ has a coefficient of thermal expansion (CTE) of 


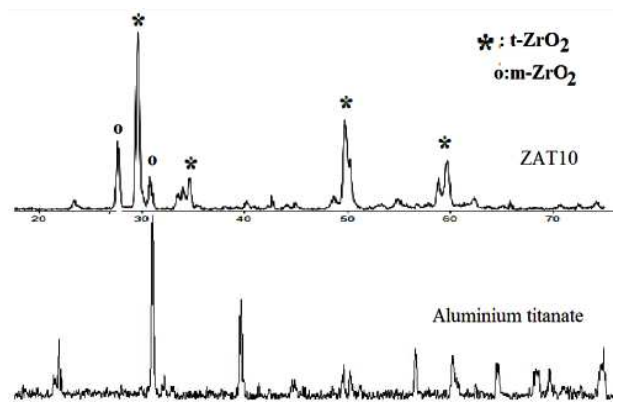

Fig. 2. XRD analyses of aluminium titanate and ZAT10.

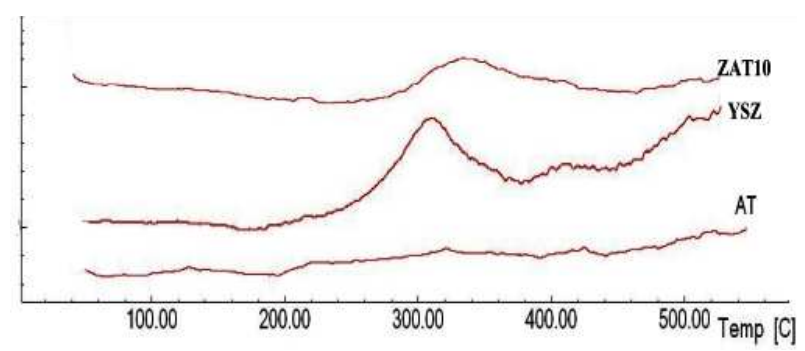

Fig. 3. DSC curves of YSZ, AT, and ZAT10 ceramics.

$1 \times 10^{-6} \mathrm{~K}^{-1}$ [17]. Addition of aluminium titanate is observed to decrease the CTE of ZAT0. Samples ZAT0 and ZAT10 have CTE of $10.8 \times 10^{-6} \mathrm{~K}^{-1}$ and $9.82 \times 10^{-6} \mathrm{~K}^{-1}$, respectively, in the range of $298-1273 \mathrm{~K}$. It is well known that a low CTE is one of the requirements for improving thermal shock resistance at elevated temperatures.

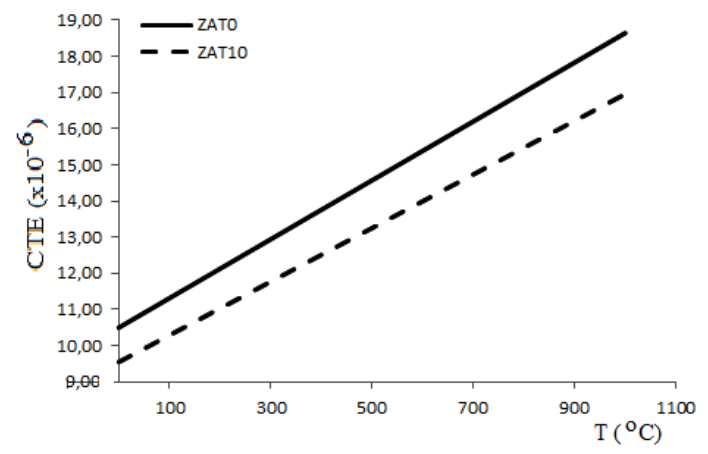

Fig. 4. CTE plots of ZAT0 and ZAT10 ceramics.

Figure 5 shows microhardness of ZAT0, ZAT5, and ZAT10 samples before thermal shock testing and after thermal shock testing. Microhardness (Shimadzu, HMV) was measured on the polished surface of the samples at room temperature. At least six individual tests with a peak load of $2000 \mathrm{~g}$ and a loading time of $20 \mathrm{~s}$ were performed for each set of composites. After thermal shock testing microhardness was measured again. The microhardness increases with increasing aluminium titanate content. In the case of ZAT10, the hardness has the

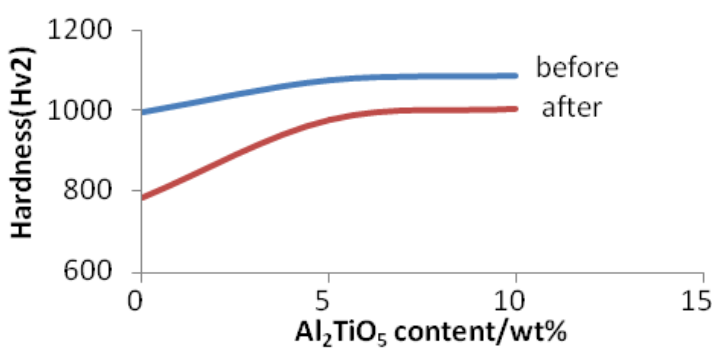

Fig. 5. Vickers microhardness ZAT0, ZAT5, and ZAT10 samples before thermal shock testing and after thermal shock testing.

biggest value (1085 $\mathrm{HV}_{2}$ ). Therefore, increasing content can be attributed to the mechanical properties like hardness. As aluminium titanate content increased thermal shock properties of the material improved. Also, the decline in the hardness of the material decreased as the aluminium titanate content increased.

\section{Conclusions}

Aluminium titanate/YSZ ceramics with different percentages of $\mathrm{Al}_{2} \mathrm{TiO}_{5}$ was prepared, microstructural and thermal properties were characterized. More denser and fewer pores structures were observed with increasing aluminum titanate content. The addition of aluminum titanate also influences the grain morphology as is observed in the microstructures of the composites. The grain size is growing as the amount of aluminum titanate increases. YSZ-AT ceramic composites show increased hardness depending upon the aluminium titanate content. Sample ZAT0 has a hardness of $994.2 \mathrm{HV}_{2}$ which increases further to $1085 \mathrm{HV}_{2}$ on addition of $10 \mathrm{wt} \%$ AT. As AT content increased, thermal shock properties of the material improved. Also, the decline in the hardness of the material decreased as the aluminium titanate content increased. XRD analysis of the sintered samples revealed that main phases are YSZ and aluminium titanate $\left(\mathrm{Al}_{2} \mathrm{TiO}_{5}\right)$. Results showed that monoclinic and tetragonal phases appeared in the samples. The CTE of the YSZ decreased as aluminium titanate was added in it. Samples ZAT0 and ZAT10 have CTE of $10.8 \times 10^{-6} \mathrm{~K}^{-1}$ and $9.82 \times 10^{-6} \mathrm{~K}^{-1}$, respectively, in the range $298-1273 \mathrm{~K}$. It is well known that a low CTE is one of the requirements for improving thermal shock resistance at elevated temperatures.

\section{References}

[1] T. Kosmac, C. Oblak, P. Jevnikar, N. Funduk, L. Marion, Dent. Mater. 15, 426 (1999).

[2] G. Dercz, K. Prusik, L. Pajak, J. Achievem. Mater. Manufactur. Eng. 18, 259 (2006).

[3] http://en.wikipedia.org/wiki/ Yttria-stabilized_zirconia .

[4] Y.-H. Koh, Y.-M. Kong, S. Kim, H.-E. Kim, J. Am. Ceram. Soc. 82, 1456 (1999). 
[5] C. Yuli, G. Gongyi, Ceram. Int. 23, 267 (1997).

[6] I. Barrios de Arenas, Reactive Sintering of Aluminum Titanate, Instituto Universitario de Tecnologia "Dr Federico Rivero Palacio", Venezuela, p. 501.

[7] I.M. Low, Z. Oo, B.H. O'Conner, Physica B 385386, 502 (2006).

[8] J.J. Meléndez-Martínez, M. Jiménez-Melendo, A. Domínguez-Rodríguez, G. Wötting, J. Europ. Ceram. Soc. 21, 63 (2001).

[9] A. Yoleva, V. Hristov, S. Djambazov, CeramicsSilikáty 53, 20 (2009).

[10] R. Papitha, M. Buchi Suresh, D. Das, R. Johnson, J. Ceram. 2013, Article ID 214974 (2012).

[11] R.D. Skala, D. Li, I.M. Low, J. Europ. Ceram. Soc. 29, 67 (2009).

[12] H.Y. Wei, L.X. Yu, Z.F. Wang, J.L. Bu, S.L. Ma, Y. Wang, Adv. Mater. Res. 194-196, 1724 (2011).
[13] T. Shimada, M. Mizuno, K. Katou, Y. Nurishi, M. Hashiba, O. Sakurada, D. Mizuno, T. Ono, Solid State Ionics 101-103, 1127 (1997).

[14] H. Gökçe, T. Boyraz, Z. Keçeli, M.L. Öveçoğlu, O. Addemir, in: 2nd International World Congress on Ceramics, International Ceramics Federation (ICF), Verona 2007, p. 56.

[15] A. Díaz-Parralejo, A. Macías-García, A.L. Ortiz, E.M. Cuerda-Correa, J. Non-Cryst. Solids 356, 175 (2010).

[16] H. Hayashi, T. Saitou, N. Maruyama, H. Inaba, K. Kawamura, M. Mori, Solid State Ionics 176, 613 (2005).

[17] I.M. Low, D. Lawrens, J. Am. Ceram. Soc. 88, 2957 (2005). 